\title{
Title: SERS of the anti-inflammatory drug piroxicam adsorbed on the surface of silver or gold colloids as nanocarrier model
}

\section{Short title: Raman and SERS spectra of Piroxicam in solution}

M. Hernandez, ${ }^{a}$ E. Corda, ${ }^{\mathrm{a}}$ J. V. Garcia-Ramos, ${ }^{\mathrm{a}}$ C. Domingo ${ }^{\mathrm{a}}$ and P. Sevilla*b,a

${ }^{*}$ Correspondence to: Paz Sevilla, Departamento de Quimica Fisica II. Facultad de Farmacia. Universidad Complutense de Madrid. 28040-Madrid. Spain.

Email:paz@ucm.es

${ }^{a}$ Instituto de Estructura de la Materia. IEM-CSIC. Serrano 121. 28006-Madrid. Spain.

${ }^{\mathrm{b}}$ Departamento de Quimica Fisica II. Facultad de Farmacia. Universidad Complutense de Madrid. 28040-Madrid. Spain.

\section{Additional supporting information:}

Three figures and one table:

- Fig. S1 shows the FT-Raman spectrum of solid piroxicam in the range 200-3500 $\mathrm{cm}^{-1}$ excited with a laser at $1064 \mathrm{~nm}$.

- Fig. S2 shows SERS spectra of piroxicam in silver colloid at $\mathrm{pH}=1,2$ and 4 and exciting with two laser lines at $442 \mathrm{~nm}$ and $532 \mathrm{~nm}$.

- Fig. S3 shows SERS spectra of piroxicam in gold colloids at $\mathrm{pH}=4$ and 7, excited at $532 \mathrm{~nm}$.

- Table I. Main Raman bands of $\beta$ Piroxicam (solid) and SERS bands on Ag colloid at different $\mathrm{pHs}$. 
Piroxicam is a non-steroidal anti-inflammatory drug (NSAID) actually used with limitations due to serious side-effects. It is poorly soluble in pure water and exhibit a minimum of four conformers according to the $\mathrm{pH}$ conditions of the solution, but not all of them are medically active. In this study we present, firstly, the Raman characterization of piroxicam in different organic solvents (DMSO, 1,4-dioxane, ethanol, 1-propanol). These results have permitted us to analyze SERS spectra of piroxicam adsorbed on gold or silver nanoparticles surface at several $\mathrm{pH}^{\prime} \mathrm{s}(1,2,4$ and 7), imitating the environment of the drug in the body, either in the gastrointestinal tract or in healthy and disease tissues. Results indicate that, below $\mathrm{pH}=7$, piroxicam is mainly in the zwiterionic conformer and molecules are oriented parallel to the noble metal surface, however at $\mathrm{pH} \geq 7$, the main specie detected is the anionic one, differently oriented with respect to the nanoparticle surface. The metal-piroxicam systems here characterized by SERS spectroscopy could constitute nanocarriers in future projects of transporting and releasing of the drug in the body.

Keywords: Piroxicam, SERS, Raman, Gold Nanoparticles, Silver Nanoparticles. 


\section{Introduction}

Piroxicam (PX), (4-hydroxy-2-methyl-N-(pyridin-2-yl)-2H-1,2-benzothiazine-3carboxamide1,1-dioxide), is a non-steroidal anti-inflammatory drug (NSAID) very efficient not only as anti-inflammatory but also as analgesic and antipyretic agent. Nevertheless, the European Medicines Agency has restricted its use since 2007 to the treatment of symptomatic relief of osteoarthritis, rheumatoid arthritis or ankylosing spondylitis, due to its gastrointestinal and skin side-effects. ${ }^{[1]}$ Related to this, a biowaiver monograph for Immediate Release Solid Oral Dosage Forms of PX, reviewing the literature data reporting its physicochemical and pharmacokinetics properties, has recently been published. ${ }^{[2]}$ There is a real interest in exploring new delivery systems for PX which improve its bioavailability and reduce its adverse effects. Nanomedicine has revealed as a potent tool to carry out drugs until the diseased cells, being noble metals, such as silver and gold, biocompatible and capable of forming nanoparticles (NPs) suitable to act as drug nanocarriers. ${ }^{[3-5]}$ Besides this, gold and silver noble metal are known to have also anti-inflammatory effect and have been used for many years in the therapy of arthritis, ${ }^{[6-8]}$ silver having antimicrobial properties as added value. ${ }^{[9]}$ Although their mechanism of action is different from that of $\mathrm{PX}$, it is clear that the efficacy of all of them in the treatment of the above mentioned diseases depend on their concentration within the joints, in the synovial fluid. ${ }^{[10,11]}$ Then it should be possible to consider the combined administration of PX and "noble metal" NPs (the last ones in a concentration lower enough to guaranteeing minimal gold/silver health toxicity) to get high efficiency in the anti-inflammatory treatments with the possibility of decreasing the side-effects and increasing the bioavailability of PX. This conjunction present several additional advantages, first, the nanometer size of the carrier permits its inclusion on more sophisticated multistep drug delivery systems and, second, taking 
advantage of the fact that silver and gold NPs support Localized Surface Plasmons, high sensitivity molecular spectroscopies - Surface-Enhanced Raman Scattering (SERS) ${ }^{[12,13]}$ and Surface-Enhanced Fluorescence $(\mathrm{SEF})^{[14]}$ - are techniques suitable for detection of drug and monitoring of delivery. But before launching such a project it is necessary to study and characterize the combined systems $(\mathrm{Au} / \mathrm{Ag}-\mathrm{PX})$ in solution, in the $\mathrm{pH}$ range the drug could meet in the body.

PX has different solid state forms, ${ }^{[15,16]}$ is poorly soluble in water and can exist in different prototropic forms in solution (Fig. 1), the equilibrium among them depending on solvent polarity, concentration and, in the case of water solutions, also on the $\mathrm{pH}^{[17,18]}$ although only the neutral forms of oxicam drugs are suggested to be medically active. ${ }^{[19]}$ Additionally, after excitation of the enol form of PX in non-polar solvents to the first electronically excited state, an intramolecular proton transfer reaction takes place generating tautomeric keto-type structure. ${ }^{[20-22]} \mathrm{PX}$ has been considered as a model substance for polymorphic and/or tautomeric drugs due to the complexity of its behavior and the variation of its physicochemical, pharmaceutical and biopharmaceutical properties (solubility, dissolution rate, etc.) depending on the structural form. ${ }^{[23]}$ It is obvious that its characterization in solution is a real challenge.

We have employed Raman and SERS for the characterization of the Au/Ag NPsPX systems in colloidal solution, at very low concentrations, similar to the ones the drug faces when delivered. Our group has already reported results on other drugs using such enhanced techniques. ${ }^{[24-26]}$

In this paper we will present and discuss the Raman spectra of PX in different organic solvents and the SERS results obtained for PX in silver and gold (aqueous) colloids and at different $\mathrm{pH}$ conditions. 
Previous studies of PX in solution have employed UV-Vis, ${ }^{[17,27]}$ fluorescence $^{[22,28]}$ or $\mathrm{NMR}^{[29]}$ spectroscopy, while Raman spectroscopy proved to be extremely useful for characterizing the different polymorphs of PX in solid state. ${ }^{[30,31]}$ Considering the large applicability of Raman and SERS spectroscopies in the pharmaceutical and biomedical fields ${ }^{[32-37]}$ we have carried out the molecular characterization (Raman) of PX in "concentrated" $\left(10^{-2} \mathrm{M}\right)$ solutions in different solvents and using different laser excitation, as the first part of the present paper. The results of such study are essential for undertaking the second part of the paper where the systems Au/Ag NPs-PX, with lower concentration of PX (around $10^{-4} \mathrm{M}$ ), have been characterized on $\mathrm{Au} / \mathrm{Ag}$ colloids, using SERS spectroscopy.

\section{Experimental section}

PX was supplied by Sigma-Aldrich with $98 \%$ grade purity. The solvents and the other reagents were supplied by Sigma-Aldrich with the highest purity.

UV-vis absorption spectra were obtained with a Varian Cary 500 UV-Vis spectrophotometer and quartz cells of $1 \mathrm{~cm}$ of path length. Raman and/or SERS spectra were carried out on a Renishaw In Via Raman instrument, equipped with a Leica microscope and an electrically cooled CCD camera, and different laser excitation $\left(\lambda_{\text {laser }}=\right.$ $325,442,532$ and $785 \mathrm{~nm}$ ). Spectral resolution was $2 \mathrm{~cm}^{-1}$. Output laser power was fixed to $10 \mathrm{~mW}(442 \mathrm{~nm}), 5 \mathrm{~mW}(532 \mathrm{~nm})$ and $15 \mathrm{~mW}(785 \mathrm{~nm})$ for collection of Raman spectra of solutions. Five scans of $10 \mathrm{~s}$ were recorded. SERS on $\mathrm{Ag}(\mathrm{Au})$ colloids, were acquired with $10(20) \mathrm{mW}(442 \mathrm{~nm}), 5(10) \mathrm{mW}(532 \mathrm{~nm})$ and $5(10)$ scans of 10 s. FT-Raman spectrum of solid PX was taken with a Bruker MultiRam spectrophotometer, with a Ge detector using a $1064 \mathrm{~nm}$ Nd:YAG laser excitation. 
Spectral resolution was set at $4 \mathrm{~cm}^{-1}$ laser power was $100 \mathrm{~mW}$ and 200 accumulations were acquired.

$\mathrm{Au}$ and $\mathrm{Ag}$ colloids were prepared by chemical reduction of $\mathrm{AgNO}_{3}$ with $\mathrm{NH}_{2} \mathrm{OH} . \mathrm{HCl}$ (hydroxylamine hydrochloride), ${ }^{[38]}$ and $\mathrm{HAuCl}_{4} \cdot 3 \mathrm{H}_{2} \mathrm{O}$ with $\mathrm{HOC}(\mathrm{COONa})\left(\mathrm{CH}_{2} \mathrm{COONa}\right)_{2} \cdot 2 \mathrm{H}_{2} \mathrm{O}$ (sodium citrate), ${ }^{[39]}$ respectively. For SERS measurements, $\mathrm{Au}$ NPs were activated adding $\mathrm{KNO}_{3}$.

Samples were prepared from stock solutions of PX with concentration $1 \times 10^{-1} \mathrm{M}$ in DMSO, and afterwards diluted: a) with the different solvents (1,4-dioxane, ethanol, 1-propanol) till final concentrations indicated for Raman measurements, and b) with water (Au/Ag colloid) for SERS measurements to get final PX concentration of $1 \times 10^{-}$ ${ }^{4} \mathrm{M}$. The $\mathrm{pH}^{\prime} \mathrm{s}$ were changed by adding $\mathrm{HCl}$ or $\mathrm{NaOH}^{[18]}$. In all cases DMSO concentration is $\leq 10 \% \mathrm{v} / \mathrm{v}$.

\section{Results and discussion}

\section{Raman spectra of solid piroxicam}

Raman spectra of our solid PX are identical when using laser excitations of 442 , 532,785 and $1064 \mathrm{~nm}$, and agree with the reported for the $\beta$ form of PX. ${ }^{[30,31]}$ No Raman signal was observed when exciting at $325 \mathrm{~nm}$, wavelength coincident with the strong electronic transition $\mathrm{S}_{0 \rightarrow 1}\left(\pi, \pi^{*}\right)$ of neutral form of PX. ${ }^{[22,40]}$ Such very large absorption originates correspondingly a large fluorescence emission, but no Resonance Raman effect was observed. The FT-Raman spectrum of solid PX in the range $200-3500 \mathrm{~cm}^{-1}$, when exciting with laser of $1064 \mathrm{~nm}$, is given in the Supplementary Material (Fig. S1). 


\section{Raman spectra of piroxicam in solution}

To our knowledge, no Raman spectra of PX in solution have previously been reported, apart from a brief mention to the Raman spectrum of an aqueous- $\mathrm{NaOH}(\mathrm{pH}=8) \mathrm{PX}$ containing solution. ${ }^{[31]}$

In order to get Raman spectra of PX in solution we need to take into account the low sensitivity of the technique, concentration larger than $10^{-2} \mathrm{M}$ being required. PX exhibits low water solubility what rules out the Raman study of PX in water. Besides, the extreme sensitivity of PX to its microenvironments ${ }^{[17]}$ recommends to use solvents with different proticity and/or polarity similarly to studies of PX in solution employing UV-Vis spectroscopy ${ }^{[27]}$, aiming also to compare the results obtained with the two molecular spectroscopic techniques. In this sense and being DMSO a well known polar and non-protic "practically universal" solvent, we studied PX in pure DMSO $\left(1 \times 10^{-1} \mathrm{M}\right)$, and in X:DMSO mixtures (X=1,4-dioxane (non-protic), ethanol and 1-propanol, both alcohols as weak polar) $\left(1 \times 10^{-2} \mathrm{M}\right)$, being in all mixtures concentration of DMSO $\leq 10 \%$ v/v (see experimental section). Fig. 2 shows the Raman spectra, excited at $532 \mathrm{~nm}$, of the solutions here studied, after subtracting the spectra of the corresponding solvents, as well as the spectrum of solid PX excited at $785 \mathrm{~nm}$. The most relevant bands are assigned to molecular moieties (T:Thiazinic ring; A: Amide; P: Pyridil ring) or groups $\left(\mathrm{CH}_{3}, \mathrm{SO}_{2}\right) .{ }^{[30,41]} \mathrm{A}$ Table with assignments is given in the Supplementary Material.

Raman marker bands of neutral species of PX, enolic closed and zwitterionic open forms, have been reported in solid samples: ${ }^{[30]} 1543$ and $1434 \mathrm{~cm}^{-1}$ (enol $\alpha$ form), 1523 and $1434 \mathrm{~cm}^{-1}$ (enol $\beta$ form) and 1465 and $1400 \mathrm{~cm}^{-1}$ (zwitterionic form in piroxicam monohydrate). In our case, in solution, while in pure DMSO the zwitterionic open form of PX is clearly evidenced by its marker bands at 1466 and $1396 \mathrm{~cm}^{-1}$ (Fig. 2e), the spectra in the other solvents, ethanol, 1-propanol and 1,4-dioxane, mainly have 
characteristics corresponding to closed neutral forms, at $\sim 1530$ and $1438 \mathrm{~cm}^{-1}$ (Fig. 1b, c and d) ${ }^{[16]}$, additionally, weak signals associated to zwitterions $\left(\sim 1470\right.$ and $\left.1400 \mathrm{~cm}^{-1}\right)$ are also observed in alcohols (Fig. 1b and c).

The two $\alpha$ and $\beta$ polymorphic forms have the same EZE intramolecular structure (see Fig. 1) of the neutral closed conformer of PX but different intermolecular bonds, which results in infinite chains for $\alpha$ form (involving the $\mathrm{OH}$ of the enol group and oxygen of the sulfoxide group) and dimers for $\beta$ form (involving the oxygen of the sulfoxide group and amide NH group). Since the amide group is differently bound by H-bonds in both forms, this justifies the different wavenumbers of the amide I (1615 $\mathrm{cm}^{-1}$ for $\alpha, 1606 \mathrm{~cm}^{-1}$ for $\left.\beta\right)$ and amide II $\left(1543 \mathrm{~cm}^{-1}\right.$ for $\alpha$ form, $1523 \mathrm{~cm}^{-1}$ for $\beta$ form). ${ }^{[30]}$ In our study of PX in different solutions, both amide I and amide II Raman bands appear between the mentioned values. In the case of DMSO, the amide I and amide II bands appear at 1608 and $1533 \mathrm{~cm}^{-1}$, whereas in the case of 1,4-dioxane they appear at 1610 and $1530 \mathrm{~cm}^{-1}$. For 1-propanol and ethanol, these bands appear at 1612 and $1530 \mathrm{~cm}^{-1}$ and at 1613 and $1532 \mathrm{~cm}^{-1}$ respectively. These differences come from differences in the molecular environment of PX in solution. While associations of infinite or two molecules, stabilized by intermolecular H-bonds, are present in solid, in solution the interaction between solvent and solute molecules controls the stabilization of the system, being these interactions of hydrogen bonding in the case of protic solvents and dipole-dipole interactions in the case of aprotic one.

Taking into account that most of the Raman bands of PX in the solutions here reported only show minor wavenumber shifts with respect to their position in the spectra of the solid form, this indicates that the interaction of PX molecules with solvents seems to be weak and very similar to those established between two drug molecules, the differences observed corresponding to changes in the intermolecular 
interactions. Thus, Raman spectra manifest that protic solvent molecules help to stabilize different intermolecular $\mathrm{H}$ bonds in PX in solution.

Our results compare quite well with the obtained using UV-Vis data ${ }^{[27]}$ where zwitterionic form of PX is reported the predominant form in formamide solution (similar to our DMSO) while the enol closed PX is predominant in 1,4-dioxane and concentrated ethanol.

\section{Resonant Raman spectrum of zwitterionic conformer of piroxicam}

The UV-Vis absorption spectra of the four PX solutions studied, but with a lower $\left(10^{-4}\right.$ M) concentration of PX to avoid signal saturation, are shown in Fig. 3. While in 1,4dioxan there is a single band $\left(\lambda_{\max }=326 \mathrm{~nm}\right)$ which corresponds to the enol closed form of PX, ${ }^{[27,42]}$ a prominent shoulder around $378 \mathrm{~nm}$ appears in the DMSO solution which, although with lower intensity, is also noticed in the alcohols and corresponds to the theoretical prediction for the zwitterionic form of PX. ${ }^{[27]}$ Having the possibility of using laser excitation at $442 \mathrm{~nm}$, we tried to get its (pre)Resonance Raman spectra which are given in Fig. 4. The zwitterion Raman marker bands of PX (1396 and $\left.1466 \mathrm{~cm}^{-1}\right)$ are undoubtedly enhanced as well as the ring out-of-plane vibration at $870 \mathrm{~cm}^{-1}$, with the general observation that bands attributable to the pyridyl moiety such as the bands at $992 \mathrm{~cm}^{-1}$, are weaker than the ones with large contribution of the thiazinic ring such as the band at $1596 \mathrm{~cm}^{-1}$.

\section{SERS spectra of piroxicam}

PX has two pKa's values, the basic pyridyl nitrogen of PX with a pKa ${ }_{1}$ value of 1.86 and the acidic 4-hydroxy proton with a $\mathrm{pKa}_{2}$ of $5.46^{[43,44]}$ (see Fig. 1). We have taken SERS spectra $\left(10^{-4} \mathrm{M}\right)$ at $\mathrm{pH}^{\prime}$ s below and above the two pKa's, i.e. $\mathrm{pH}=1,2,4$ and 7 using silver and gold colloids. Fig. 5 shows the results obtained with Ag colloids using 
laser excitation at $532 \mathrm{~nm}$, normalized to the $680 \mathrm{~cm}^{-1}$ SERS band of DMSO. SERS spectra of PX on Au colloids, excited at $785 \mathrm{~nm}$, were also obtained and are given as illustration in the Supplementary Material. They show similar patterns than those obtained using silver NPs and, despite some band shifts, it seems that PX behaves in the same way with respect to both, Ag and Au NPs surfaces. However, the SERS spectra of PX on Au colloids have lower spectral quality than the ones on Ag colloids because they exhibit much lower intensity and, additionally, spectra show "contamination" due to the reductor and the aggregation agents (sodium citrate and sodium nitrate respectively) employed in the preparation of the colloids. Thus, we will focus the discussion on the SERS spectra on Ag colloids.

It is established in the literature that piroxicam in aqueous solutions and within the $\mathrm{pH}$ range $0,9-7$ can exist as a zwitterion in different ratios, while for $\mathrm{pH}>7$, only the anionic form is present. ${ }^{[45]}$ The analysis of the SERS spectra recorded in this work (Fig. 5) allows to realize that from $\mathrm{pH}=1$ to $\mathrm{pH}=4$, the zwitterionic form (bands at $\sim 1400$ and $1465 \mathrm{~cm}^{-1}$ ) becomes predominant as the $\mathrm{pH}$ increases. The zwitterionic form is revealed as well by the presence of a couple of equal intensity Raman bands at $\sim 1010$ and 1034 $\mathrm{cm}^{-1}$ assigned to the pyridinium group. ${ }^{[41]}$ In the SERS spectrum at $\mathrm{pH}=1$, bands in the 1400-1500 $\mathrm{cm}^{-1}$ region have a extremely low intensity, as it happens in the Raman spectrum of solid PX hydrochloride ${ }^{[31]}$ where PX is in the cationic form. It could be suggested that the cationic form of $\mathrm{PX}$, coexistent with the zwitterionic one at $\mathrm{pH} \sim 0.9$ according to literature $^{[45]}$ is also inferred from our SERS spectra at $\mathrm{pH}=1$.

The interaction of PX with the silver (gold) surface seems to implicate the amidic group and the thiazinic moiety, according to the changes observed in the 1600$1500 \mathrm{~cm}^{-1}$ region of the SERS spectra when compared with the Raman spectrum of solid PX. Such changes suggest different $\pi$ conjugation of both groups which can be 
related to the proximity of the $\mathrm{C}=\mathrm{O}$ group to the metal surface. Simultaneously, some bands associated to the pyridinic ring $\left(\sim 1217,650\right.$ and $\left.405 \mathrm{~cm}^{-1}\right)$ hardly show shifts in the presence of the metal surface then suggesting that such part of the PX molecule does not interact with the metal NPs.

It is well known that the electromagnetic field near to the metal surface has larger intensity in the perpendicular direction than in the paralell one. ${ }^{[12]}$ Due to this fact, Raman bands corresponding to molecular vibrations "perpendicular" to the surface are more enhanced in SERS spectroscopy than the paralell ones, and reversed. Such "surface selection rules" can be used to infer, from the SERS data, the relative orientation of a molecule on a metal surface. Thus, a great intensification in the SERS spectrum of in-plane vibrations in planar molecules, such as the $\delta\left(\mathrm{CH}_{3}\right)$ (in-plane bending) indicates a perpendicular orientation of the molecule. ${ }^{[25]}$ In our system, where neutral forms of Piroxicam are planar molecules, the $\delta\left(\mathrm{CH}_{3}\right)$ band, at $\sim 1434 \mathrm{~cm}^{-1}$ in the Raman spectra of solid and solutions, shows a dramatic decrease of intensity in the SERS spectrum. This fact could indicate a relatively paralell orientation of PX to the metallic surface, a fact which seems to be endorsed by the slight enhancement of some out of plane bands of PX ( 940, 830 and $\left.770 \mathrm{~cm}^{-1}\right)$ in the SERS spectra.

The SERS spectrum at $\mathrm{pH}=7$ (Fig 5) has a different pattern and is considerably weaker than at lower pH's. It compares quite well with the Raman spectrum reported for the sodium salt of $\mathrm{PX}$ in the $1700-1200 \mathrm{~cm}^{-1}$ region ${ }^{[31]}$, then confirming the existence of the anionic form at $\mathrm{pH}=7$. Besides, the existence of a pyridyl group is manifested by the presence of only one strong band in the $990-1050 \mathrm{~cm}^{-1}$ range. The global low intensity of the SERS spectrum at $\mathrm{pH}=7$ is probably related to an interaction and orientation of the PX anionic form to the metal surface different from the zwitterionic form. It must be noted that in the anionic form of PX both aromatic 
moieties are no longer co-planar. Taking into account that one of the few bands "enhanced" is the in-plane pyridil ring breathing $\left(\sim 1000 \mathrm{~cm}^{-1}\right)$, it could be inferred that such moiety is closer to the metal and perpendicularly oriented to the metal surface.

We have also obtained SERS spectra using laser excitation at $442 \mathrm{~nm}$ The results are given in the Supplementary Material. No "(pre)-Resonance" Raman of the zwitterionic form was observed in the SERS spectra excited at $442 \mathrm{~nm}$. Larger enhancement of the Raman signals was obtained for $532 \mathrm{~nm}$, as a consequence of the resonant excitation of the LSP of the Ag nanoparticles at such wavelength. At $442 \mathrm{~nm}$ we were out of the LSP resonance.

\section{Conclusions}

First results of Raman in solution and SERS in gold and silver colloid of antiinflammatory drug PX are presented and analyzed. Four different $\mathrm{pH}$ conditions according to the pKa's of the drug have been used. Typical bands of thiazinic ring, amide and pyridil group have been identified in the Raman spectra of PX in solution using four solvents with different polarity. While spectra recorded using DMSO solutions shows bands corresponding to the zwiterionic conformer, when 1,4-dioxane, 1-propanol or ethanol are used as solvents spectra indicate mainly the presence of closed neutral forms of PX.

SERS spectra of PX in gold and silver colloids show similar trends indicating same conformer and orientation of drug to both noble metal NPs. At acidic $\mathrm{pH}=1$ bands of open anionic and zwiterionic conformers are identified. At $\mathrm{pH}^{\prime} \mathrm{s}$ in the range 2-4, bands dominating the spectra correspond to zwiterionic form with a relative parallel orientation of the aromatic moieties to the metal NPs surface. At $\mathrm{pH}=7$ few and weak bands appear in the SERS spectrum, its analysis 
indicating the presence of the anionic form of PX differently oriented to the metal surface. These studies deep in the knowledge of systems Au NPs-PX and AgNPsPX characterizing the structure and orientation of the PX molecules adsorbed on the metal surface and could constitute an essential step for their future use in biotechnology and nanomedicine.

\section{Acknowledgements}

This work was supported by the Spanish Ministerio de Economía $y$ Competitividad (grant FIS2014-52212-R).

\section{References}

[1] E. M. Agency 2007.

http://www.ema.europa.eu/ema/index.jsp?curl=pages/medicines/human/referrals/ Piroxicam/human_referral_000109.jsp\&mid=WC0b01ac05805c516f

[2] I. E. Shohin, J. I. Kulinich, G. V. Ramenskaya, B. Abrahamsson, S. Kopp, P. Langguth, J. E. Polli, V. P. Shah, D. W. Groot, D. M. Barends, J. B. Dressman J. Pharm. Sci. 2014, 103, 367.

[3] D. J. A. Crommelin, A. T. Florence Int. J. Pharm. 2013, 454, 496.

[4] M. Hernandez, G. Recio, R. J. Martin-Palma, J. V. Garcia-Ramos, C. Domingo, P. Sevilla Nanoscale Res. Lett. 2012, 7.

[5] A. J. Mieszawska, W. J. M. Mulder, Z. A. Fayad, D. P. Cormode Mol. Pharm. 2013, 10, 831.

[6] G. R. Burmester Z. Rheumatol. 2001, 60, 167.

[7] A. Yilma, S. Singh, S. Dixit, V. Dennis Int. J. Nanomed. 2013, 8, 2421.

[8] O. Seifert, A. Matussek, F. Sjogren, R. Geffers, C. D. Anderson J. Inflamm. 2012, 9.

[9] A. D. Russell, W. B. Hugo Prog. Med. Chem. 1994, 31, 351.

[10] Z. Trnavska, K. Trnavsky, D. Zlnay Eur. J. Clin. Pharm. 1984, 26, 457.

[11] B. Bannwarth, P. Bertin, F. Pehourcq, T. Schaeverbeke, P. Gillet, G. Lefrancois, R. Treves, J. Dehais, P. Netter, A. Gaucher Int. J. Clin. Pharm. Ther. 2001, 39, 33.

[12] R. Aroca Surface-Enhanced Vibrational Spectroscopy; John Wiley \& Sons, Ltd, 2007.

[13] E. C. Le Ru, P. G. Etchegoin Principles of surface-enhanced Raman spectroscopy and related plasmonic effects; Elsevier: Amsterdam, 2009. 
[14] J. R. Lakowicz, K. Ray, M. Chowdhury, H. Szmacinski, Y. Fu, J. Zhang, K. Nowaczyk Analyst 2008, 133, 1308.

[15] A. R. Sheth, S. Bates Crys. Growth Des. 2004, 4, 1091.

[16] F. Vrečer, M. Vrbinc, A. Meden Int. J. Pharm. 2003, 256, 3.

[17] R. Banerjee, M. Sarkar J. Lumines. 2002, 99, 255.

[18] H. Chakraborty, M. Sarkar Biophys. Chem. 2005, 117, 79.

[19] M. Gil, A. Douhal Chem. Phys. 2008, 350, 179.

[20] D. W. Cho, Y. H. Kim, M. Yoon, S. C. Jeoung, D. Kim Chem. Phys. Lett. 1994, 226, 275.

[21] M. Gil, A. Douhal J. Phys. Chem. A 2008, 112, 8231.

[22] M. Yoon, H. Choi, H. Kwon, K. Park Bull. Korean Chem. Soc. 1988, 3, 171.

[23] U. Paaver, A. Lust, S. Mirza, J. Rantanen, P. Veski, J. Heinämäki, K. Kogermann Int. J. Pharm. 2012, 431, 111.

[24] P. Sevilla, R. De-Llanos, C. Domingo, S. Sanchez-Cortes, J. V. GarciaRamos In Plasmonics in Biology and Medicine VII; VoDinh T., Lakowicz J. R., Eds.; SPIE-Int Soc Optical Engineering: Bellingham, 2010; Vol. 7577, p 757714.

[25] G. Fabriciova, E. Lopez-Tobar, M. V. Cañamares, M. Backor, S. SanchezCortes Vib. Spectrosc. 2012, 63, 477.

[26] P. Sevilla, F. Garcia-Blanco, J. V. Garcia-Ramos, S. Sanchez-Cortes Phys. Chem. Chem. Phys. 2009, 11, 8342.

[27] M. Franco-Pérez, L. I. Reyes-García, R. Moya-Hernández, R. GómezBalderas Int. J. Quantum Chem. 2012, 112, 3637.

[28] K. F. De Souza, J. A. Martins, F. B. T. Pessine, R. Custodio Spectroc. Acta. Pt. A-Molec. Biomolec. Spectr. 2010, 75, 901.

[29] J. M. Geckle Magn. Reson.Chem. 1989, 27, 150.

[30] E. Redenti, M. Zanol, P. Ventura, G. Fronza, A. Comotti, P. Taddei, A. Bertoluzza Biospectroscopy 1999, 5, 243.

[31] P. Taddei, A. Torreggiani, R. Simoni Biopolymers 2001, 62, 68.

[32] M. Baia, S. Astilean, T. Iliescu Raman and SERS investigations of pharmaceuticals; Springer: Berlin Heidelberg, 2008.

[33] S. C. Pînzaru, I. E. Pavel In Surface Enhanced Raman Spectroscopy; WileyVCH Verlag GmbH \& Co. KGaA: 2010, p 129.

[34] J. Aaltonen, K. C. Gordon, C. J. Strachan, T. Rades Int. J. Pharm. 2008, $364,159$.

[35] I. Shadi, M. Warner, R. Goodacre Int. Pharm. Ind. 2011, 3, 114.

[36] A. Lust, S. Lakio, J. Vintsevits, J. Kozlova, P. Veski, J. Heinämäki, K. Kogermann Int. J. Pharm. 2013, 456, 41.

[37] Š. Bálint, S. Rao, V. Huntošová, P. Miškovský, D. Petrov, M. M. Sánchez J. Biomed. Opt. 2010, 15, 027005.

[38] N. Leopold, B. Lendl J. Phys. Chem. B 2003, 107, 5723.

[39] G. Frens Nat. Phys. Sci. 1973, 241, 20.

[40] R. Banerjee, H. Chakraborty, M. Sarkar Spectroc. Acta Pt. A-Molec. Biomolec. 2003, 59, 1213.

[41] G. Socrates Infrared and Raman Characteristic Group Frequencies: Tables and Charts; John Wiley \& Sons: Chichester, 2001.

[42] S. M. Andrade, S. M. B. Costa Phys. Chem. Chem. Phys. 1999, 1, 4213.

[43] R. S. Tsai, P. A. Carrupt, N. Eltayar, Y. Giroud, P. Andrade, B. Testa, F. Bree, J. P. Tillement Helv. Chim. Acta 1993, 76, 842. 
[44] K. Takacsnovak, J. Kokosi, B. Podanyi, B. Noszal, R. S. Tsai, G. Lisa, P. A. Carrupt, B. Testa Helv. Chim. Acta 1995, 78, 553.

[45] S. Rozou, A. Voulgari, E. Antoniadou-Vyza Eur. J. Pharm. Sciences 2004, 21,661 .

\section{Figure captions:}

Fig. 1 Structure, numbering and acid-base equilibrium of piroxicam (4hydroxy-2-methyl-N-(pyridin-2-yl)-2H-1,2-benzothiazine-3-carboxamide1,1dioxide). ${ }^{a}$ [43]). ${ }^{b}$ [44] Planar conformation shown is defined as EZE referred to bonds $\mathrm{C}(3)-\mathrm{C}(14), \mathrm{C}(14)-\mathrm{N}(16)$ and $\mathrm{N}(16)-\mathrm{C}\left(2^{\prime}\right)$.

Fig. 2 Raman spectra of piroxicam. a) Solid excited at $785 \mathrm{~nm}$. In solution $\left(10^{-2} \mathrm{M}\right)$, in all solutions concentration of DMSO is less than $10 \% \mathrm{v} / \mathrm{v}$, excited at $532 \mathrm{~nm}$ after subtracting the spectra of the corresponding solvents, b) ethanol, c) 1-propanol, d) 1,4-dioxane, e) DMSO. All spectra are normalized to the $1592 \mathrm{~cm}^{-}$

${ }^{1}$ band. ${ }^{2}$ artifacts due to solvents. (- - ) bands characteristic of the zwitterionic form of PX; $(-\cdot-)$ bands characteristic of the neutral form of PX.

Fig. 3 UV-Vis absorption spectra of piroxicam in solution $\left(10^{-4} \mathrm{M}\right)$, in all solutions concentration of DMSO is less than 10\% v/v. (-) DMSO, (- - - ) 1propanol, $(-\cdot-)$ ethanol, $(---)$ 1,4-dioxane. 
Fig. 4 Raman spectra of piroxicam in DMSO $\left(10^{-1} \mathrm{M}\right)$ excited at: a) 442 $\mathrm{nm}$, b) $532 \mathrm{~nm}$, c) $785 \mathrm{~nm}$. All spectra are normalized to the $1530 \mathrm{~cm}^{-1}$ band.

Fig. 5 SERS spectra of piroxicam $\left(10^{-4} \mathrm{M}\right)$ in $\mathrm{Ag}$ colloids, at different pH's using laser excitation line at $532 \mathrm{~nm}$. Spectra are normalized to the DMSO band at $680 \mathrm{~cm}^{-1}$. 



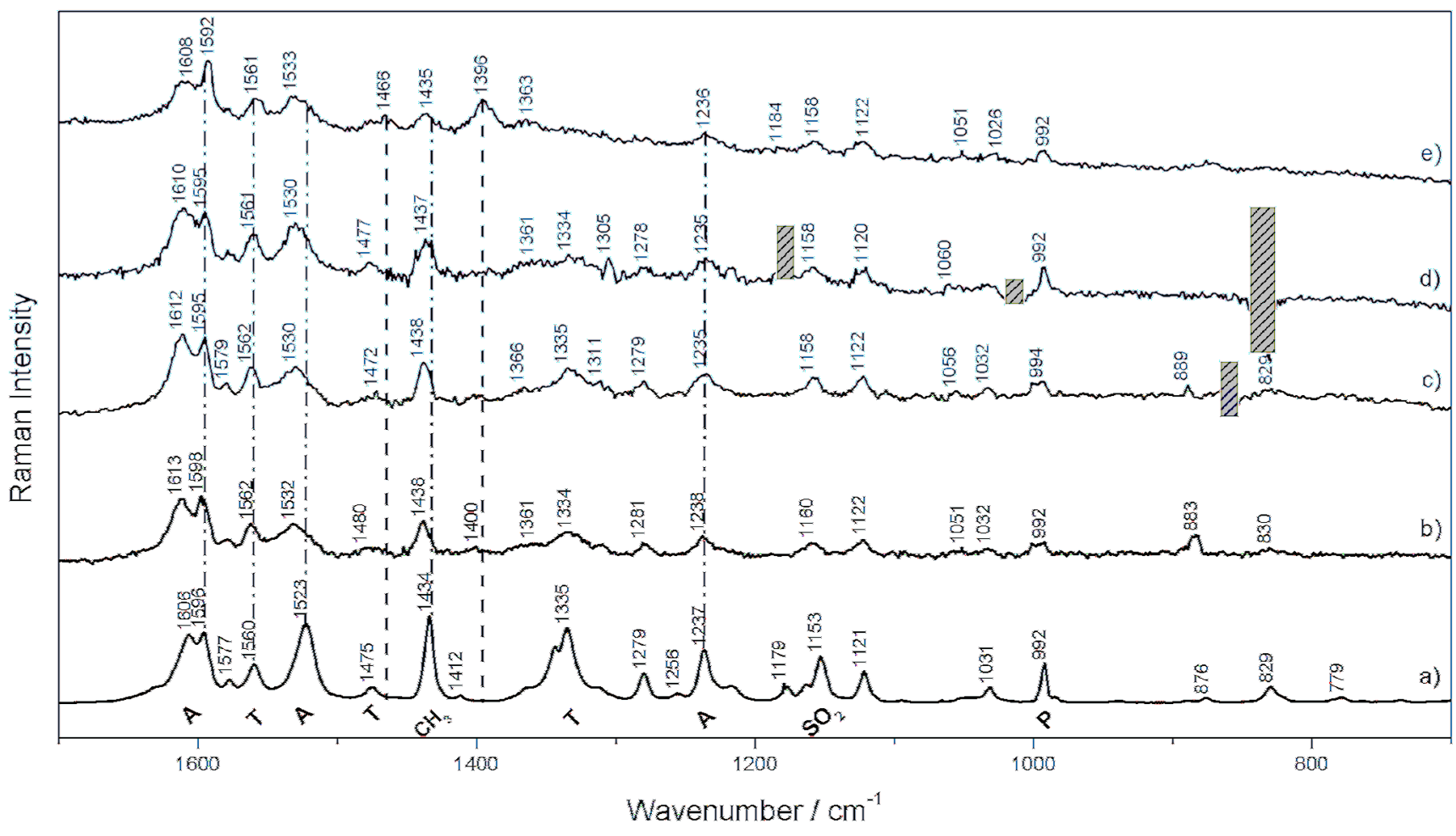




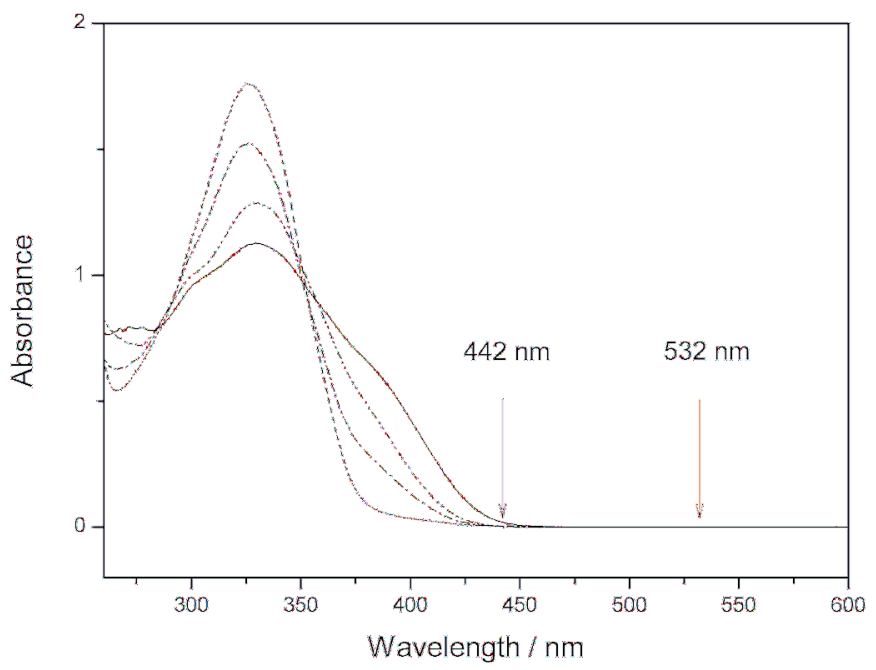




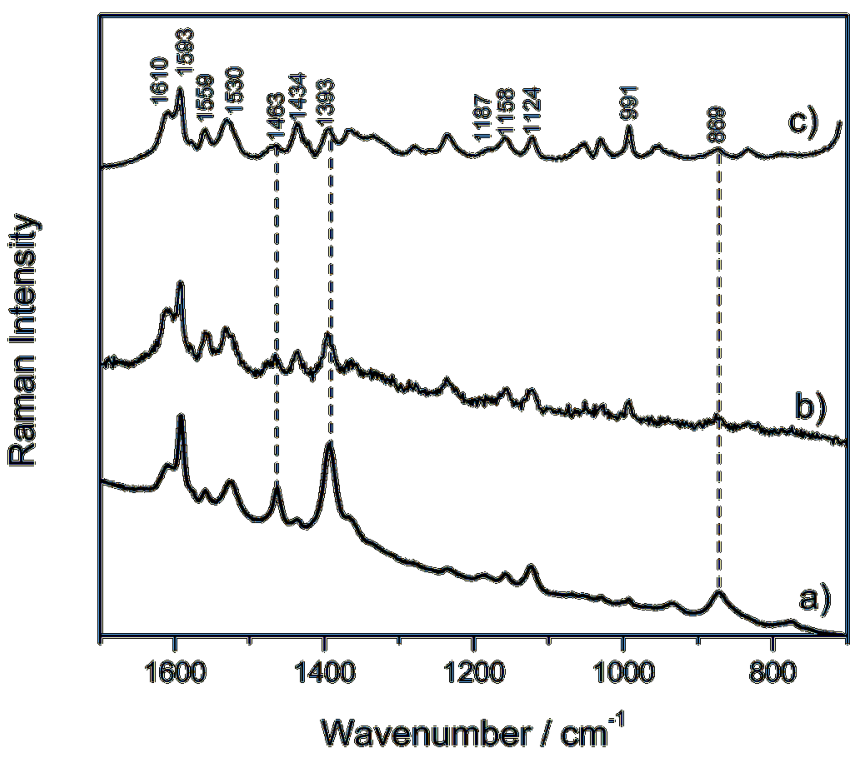




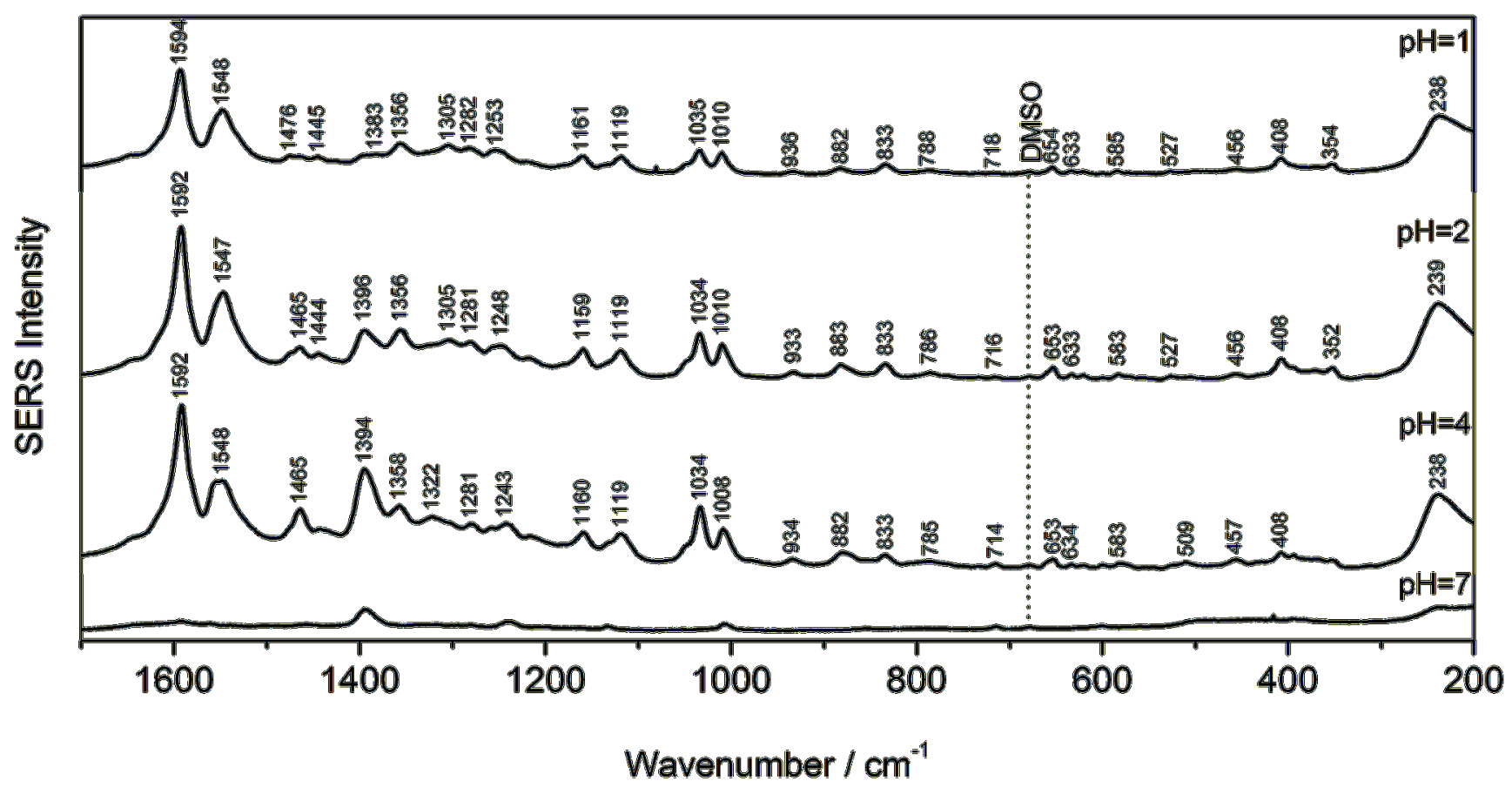

